\title{
NEGRA ESPALDA DE SEBALD
}

\author{
Matías García Rodríguez \\ Universidade de Santiago de Compostela
}

EXPOSICIÓN: Las variaciones Sebald / Sebald Variations. Centre de Cultura Contemporània de Barcelona, 10 de marzo - 26 de julio de 2015. Comisario: Jorge Carrión. Dirección de proyecto: Rosa Ferré.

Allá por 1927, Virginia Woolf declaraba el agotamiento de la biografía victoriana. Pequeños libros geniales como Some People, de Harold Nicolson, informaban a su entender de un cambio de perspectiva que había llevado al biógrafo de la crónica al arte. La cuestión, tal y como la plantea Woolf, resulta tan clara como ineludible: la biografía debe reflejar a un mismo tiempo verdad y personalidad. Ahora bien,

... if we think of truth as something of granite-like solidarity and of personality as something of rainbow-like intangibility and reflect that the aim of biography is to weld these two into one seamless whole, we shall admit that the problem is a stiff one and that we need not wonder if biographers have for the most part failed to solve it. ${ }^{1}$

Es cierto, la verdad de los museos ${ }^{2}$ resulta fascinante, pero difícilmente constituye una meta en sí misma. La dificultad estriba en la construcción de proyectos biográficos cuyo arte sea "suficientemente sutil y honesto" como para no dejar escapar, en aras del dato, "aquello que ha sido lo más real" en la vida del retratado, y que por lo general y de manera evidente es ajeno a toda lógica ${ }^{3}$.

Lo recuerdo porque la exposición -comisariada por Jorge Carrión- que recientemente ha organizado el Centre de Cultura Contemporània de Barcelona a propósito del escritor alemán W. G. Sebald ha puesto en juego estas cuestiones, de manera tal que ha abierto el "problema Sebald" evitando lo que un evento de este tipo pudiera haber hecho por cerrarlo, reforzando imaginarios previos y amontonando datos para, en último término, clausurar sentidos. Por lo demás, tanto esta exposición como su celebración en el contexto del extraordinario y ya relativamente longevo festival Kosmópolis, vienen a continuar propuestas tan acertadas como la que en 2013 organizara el CCCB en torno a Roberto Bolaño4.

La regresión potencialmente infinita de esta clase de exposiciones (de Sebald a lo "sebaldiano" y de nuevo a Sebald, hasta que ya no quede nada) amenaza siempre con detenerse en la rentabilización de un previo reconocimiento (la determinación de lo que lo "sebaldiano" pueda $\operatorname{ser}^{5}$ ) y, en consecuencia, constituir un ejercicio interesante para el mitómano pero fútil por lo que respecta al juego que toda obra abre. De lo que se trata, pues, es de hallar la manera justa de repetir al autor, de adecuarse a su obra sin dejar de avanzar, operando todos esos factores que, a la manera de reflejos y a través de nuevas obras, ejerzan de (algunos de) los Sebald posibles, y que han comparecido en el CCCB bajo la forma del naturalista atormentado, el explorador testarudo o el académico meticuloso. $Y$ es que, como decía también Virginia Woolf, sin duda es en los espejos de nuestros amigos donde con mayor fuerza vivimos ${ }^{6}$.

Gracias a este productivo paralaje, la exposición conforma una especie de archivo de las heterotopías sebaldianas, compuesto por las obras de muy diferentes artistas. No cabe duda, a día de hoy, de que el término "archivo" resulta ambiguo (por sobreexpuesto, cuando no sobredeterminado), pero no por ello parece menos adecuado su asociación con el trabajo de Sebald, en particular por lo que respecta a las lógicas centrípeto-centrífugas del documento como objeto de reflexión en torno al cual la obra emerge como correlato problemático. Se trata de una metodología que produjera ya inte- 


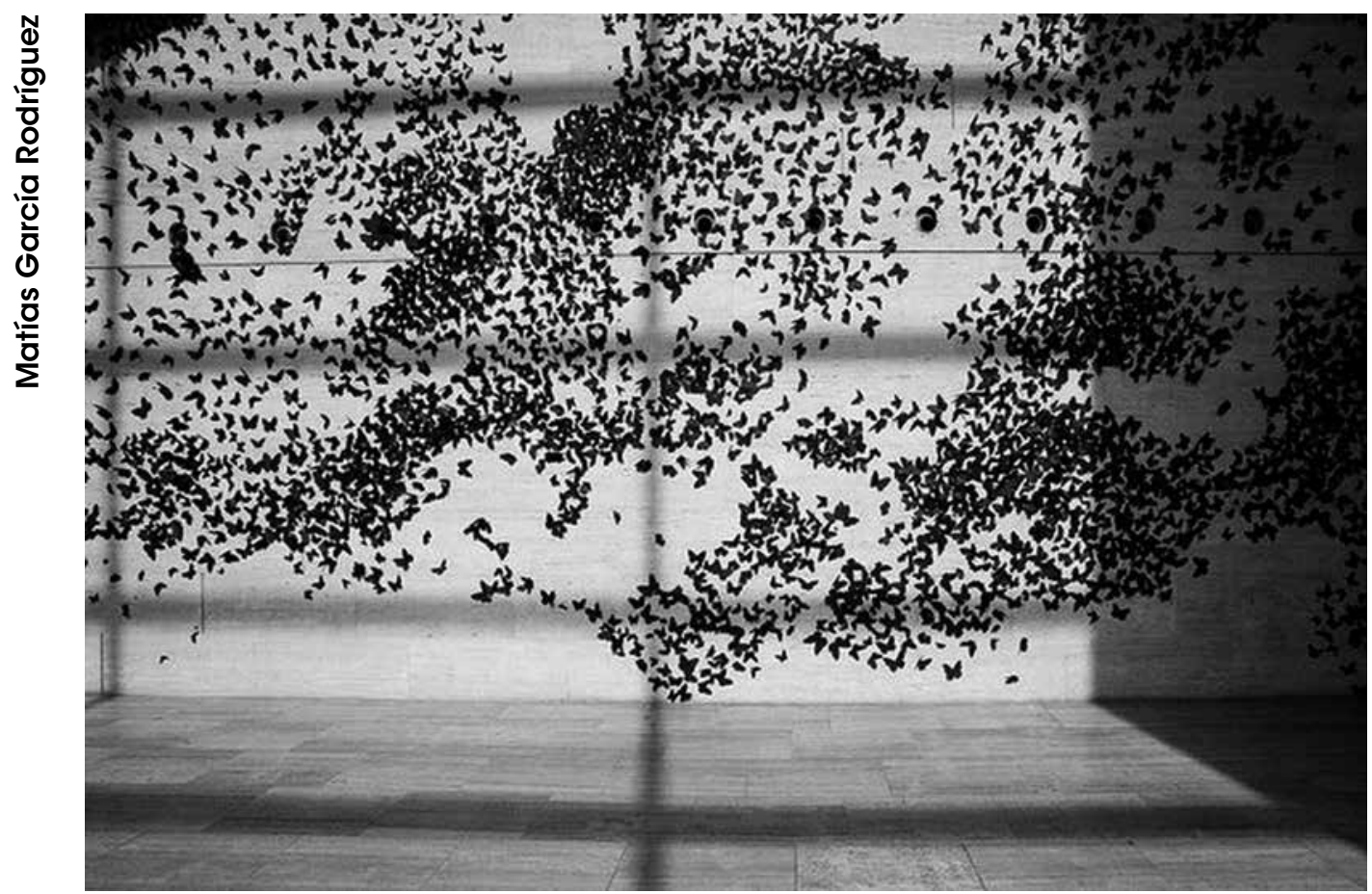

resantes diálogos, particularmente en el caso de Tacita Dean ${ }^{7}$, y que ahora aflora en la exposición del CCCB en la obra de Mariana Castillo Deball (1975), quien ha realizado una investigación sobre las muy sebaldianas estaciones de ferrocarril, en su tensión entre lo perenne y lo transitorio.

Por otro lado, la pregunta por la Historia y sus restos es también la que formula Andrea Geyer (1971), artista que ya venía tratando cuestiones como la identificación, la responsabilidad individual y la construcción políticocultural del tiempo, y que en su vídeo Gezeiten (2015) construye, a partir de un álbum familiar, una reflexión sobre la mujer en la segunda mitad del siglo $X X$, en un juego ambiguo entre lo individual y lo histórico de poderosas resonancias sebaldianas.

Un viaje familiar, si bien de muy diferente cariz, es también lo que nos propone Taryn Simon (1975) en A Living Man Declared Dead and Other Chapters I-XVIII (2008-2011), resultado de su recorrido por diferentes lugares del mundo reuniendo información sobre dieciocho linajes sanguíneos que ejercen de fantasmas del futu- ro tanto como de pequeños relatos locales que Simon salva del olvido, y a través de los cuales formula preguntas acerca de las condiciones de posibilidad de la aprehensión documental y las dimensiones del extrañamiento categorial, en una reflexión de nuevo sebaldiana a propósito de los lindes de la taxonomía misma.

Si una ausencia era la que había dado comienzo al proyecto de Simon, será también un vacío el que explique The J. Street Project (2002-2005) de Susan Hiller (1940), frecuente caminante de la memoria quien, en esta serie de fotografías, registra paisajes rurales en apariencia ordinarios que sin embargo sobredetermina al revelarnos sus nombres, invariablemente compuestos por o derivados de la palabra Jude (judío); nombres que, como ella misma nos dice, "todavía se utilizan localmente y aparecen en mapas, pero han desaparecido de los letreros de la calle, al igual que las personas a las que aluden"8.

De paisajes en apariencia inconexos da también cuenta Trevor Paglen (1974), quien aquí documenta, o más bien registra, instalaciones de- 
pendientes de agencias gubernamentales enclavadas en lugares de apariencia bucólica, como pequeños ojos de la Historia acechando entre la Naturaleza. Volviendo al mapa, nos encontramos también con My Ghost (2015), obra creada ex profeso por Jeremy Wood (1976), pionero en la experimentación gráfica con las herramientas brindadas por el GPS (en esa actitud entre arte e investigación tan propia de Sebald y los "sebaldianos" aquí congregados) y que aquí nos ofrece, sobre una pieza de seda negra (en alusión a Los anillos de Saturno) quince años de registros propios a través de la ciudad de Londres.

Tanto el archivo de huellas de Hiller como las investigaciones de Paglen emulan un movimiento que la ocasión invita a emparentar con Sebald, si bien de hecho es característico de una actitud, la de los hijos y nietos del trauma de Europa que, como Sebald, pero también Bernhard o Kertész, se enfrentaron a un pasado brumoso, marcado por esa niebla densa y húmeda que, como sabemos con Breman, es propia de la Modernidad. Tenía razón Sebald al decir que la representación de la historia se fundamentaba en una falsificación de la perspectiva, y acertó también al proceder por medio de retales, a través de la composición de historias de temporalidad "vertical" en donde el tiempo es congelado para abrir paso a recuerdos que nos llevan de aquí a allá a través de una memoria imprecisa, vaga, llena de puntos ciegos y fantasmas que, apenas asoman bajo el repentino fulgor de un desvelamiento ${ }^{9}$, enseguida nos vuelven a sumergir en la duda. De ahí esa característica contención y sobriedad de cierta literatura alemana de posguerra (o hija de la posguerra) y de la reunificación (período en el que comenzó Sebald a escribir ficción), y también de ahí que Jorge Carrión apunte que "no es la suya una nostalgia o una melancolía romántica, sino anti-románticas. Rechaza la frase impactante, el clímax narrativo, la épica, el desgarro, la intensidad de la filosofía y de la poesía alemanas que prepararon sin saberlo la catástrofe" ${ }^{10}$, y precisamente es esa melancolía distante la que pone también en juego el viaje de Guido van der Werve (1977) en Nummer veertien, home (2012).

Ambas inercias, la constatación de una disolución inevitable y la reconstrucción testaru- da del final de la partida (algo de beckettiano hay también en Sebald) se encuentran aquí representadas. Por una parte, nos topamos con obras como $0^{\circ} 00$ Navigation (2009), pieza que encuentra aquí una poderosa caja de resonancia que le otorga matices insospechados. Desde Peacehaven (Sussex) hasta Cleethorpes (Lincolnshire), Simon Faithfull (1966) recorre Inglaterra (incidentalmente, algunos de los paisajes en los que el propio Sebald vivió) siguiendo la línea de longitud $0^{\circ} 00^{\prime} 00^{\prime \prime}$, esto es, la demarcación del meridiano de Greenwich.

En una suerte de ejercicio anti-psicogeográfico (en la medida en que el mapa se impone sobre el territorio), Faithfull sortea obstáculos (el mundo, que se obstina en bloquear su camino); cruza propiedades, trepa verjas, vadea ríos y atraviesa edificios colándose por las ventanas, todo ello a lo largo de este constructo hipotético que, como el mismo artista dice, "trata como si fuera un fenómeno real". Resulta difícil, ante su obra, no pensar en títulos como Austerlitz, en esa constatación de los límites del archivo que aquí Faithfull cuestiona también, si bien en cierto sentido a la inversa, pues desdibuja la validez del mapa precisamente al tomárselo excesivamente en serio, llevándolo hasta sus últimas (y absurdas) consecuencias.

Esta testarudez, sin embargo, se enfrenta a un límite que, en términos "de archivo", no es otro que la disolución de aquello que, como en un golpe de humo, es lo propio de lo que se deshace sin llegar nunca a desvanecerse del todo, como la memoria alemana sobre la que Sebald escribió. Mucho de esta miríada impotente, fascinante pero inasible, atrayente pero al mismo tiempo siniestra, está presente en la obra del mexicano Carlos Amorales (1970). Sebald, sensible a las cuestiones de composición (es ahí donde está la clave de bóveda de su recurso a la intertextualidad y la combinación de texto e imagen), seguramente habría encontrado un cierto placer en el hecho de que Amorales, tras años de invadir galerías y museos con cientos y miles de siluetas de mariposas negras (que él mismo recorta), descubriera más tarde la obra del alemán, y el lugar tan singular que ocupa este insecto en obras como Austerlitz o Los anillos de Saturno. Sin resultar particularmente innovador 
en su uso entre plástico y metafórico de la imagen de la mariposa (pensemos en Diderot y la Encyclopédie, en Goethe, o incluso en Lewis Carroll), la disposición de sus 30,000 tenaces y frágiles siluetas a lo largo de las paredes del CCCB constituye sin duda uno de los grandes aciertos de la exposición.

De imágenes e imaginarios nos hablan también Fernando Sánchez Castillo (1970) y Núria Güell. El primero, en su pregunta ya recurrente en torno al monumento como problemático depósito de memorias, presenta en Monumentos ciegos (2007-2015) una nueva vuelta de tuerca a las relaciones entre arte, poder y memoria a través, en este caso, de maquetas de edificios protegidos durante el asedio fascista a Madrid. Por su parte, Núria Güell (1981) nos ofrece en su vídeo Resurrección una nueva reflexión institucional sobre la noción de legalidad en clave sin duda irónica (Güell hizo desaparecer a lo largo de una cuneta diversos objetos de propaganda franquista que ella misma había comprado a la Fundación Francisco Franco con una tarjeta de crédito a nombre de un maquis asesinado en 1939, objetos que, en consecuencia, fueron enviados pero nunca cobrados).

Se trata, en definitiva, de una exposición pertinente y productiva. Sin resultar inmune a ciertas e inevitables inercias del ejercicio retros- pectivo, los aciertos marcaron la pauta, como por lo demás refleja el propio catálogo, en el que Jorge Carrión se atreve a matizar ese fetiche sacrosanto de la originalidad que tanto distorsiona la imagen del escritor caído en gracia, pero que no deja de ser, como la memoria, una mera cuestión de composición y, en consecuencia, un efecto óptico. Como señala Carrión, Sebald es parte de diferentes linajes, entre los que cabe citar a Benjamin y a Breton, a Chatwin y a Magris, a Kafka y a Handke ${ }^{11}$, como también a Bernhard, a Walser, o incluso a cierto Javier Marías (Negra espalda del tiempo, por ejemplo, título que es a su vez genial traducción de Shakespeare). A la lista de buenas decisiones debemos sumar no sólo la inclusión de un texto de uno de los más profundos conocedores de la obra de Sebald (J. J. Long ${ }^{12}$ ) sino, de manera particular, la transcripción de una conversación breve pero muy reveladora entre Pablo Helguera y el historiador del arte James Elkins, singular pero muy pertinentemente crítico con el legado sebaldiano ${ }^{13}$.

Cabría resaltar, para terminar, la disposición en la página web del CCCB de toda una serie de entrevistas relacionadas con la exposición, la conformación del blog Sebaldiana, y, desde luego, la propia organización en paralelo de numerosas actividades en torno a Sebald (conferencias, seminarios y proyecciones, en particular).

\section{NOTAS}

1 WOOLF, Virginia, "The New Biography" [1927], en Granite and Rainbow, Harcourt, Brace \& Company, New York, 1958, p. 149.

2 "For the truth [...] which biography demands, is truth in its hardest, most obdurate form; it is truth as truth is to be found in the British Museum; it is truth out of which all vapour of falsehood has been pressed by the weight of research". Ibidem.

3 "Consider one's own life; pass under review a few years that one has actually lived. Consider how Lord Morley would have expounded them; how Sir Sidney Lee would have documented them; how strangely all that has been most real in them would have slipped through their fingers. Nor can we name the biographer whose art is subtle and bold enough to present that queer amalgamation of dream and reality, that perpetual marriage of granite and rainbow. His method still remains to be discovered". WOOLF, "The New Biography"..., p. 155.

${ }^{4}$ Nos referimos a la exposición Arxiu Bolaño. 1977-2003 (5 de marzo 30 de junio de 2013), comisariada por Valérie Miles y Juan Insua.

${ }^{5}$ Lo que interesa no es tanto el Sebald constituido (su obra, vista por el lado del reconocimiento) como el Sebald constituyente, el cual Vicenç Villatoro evoca al hablar de su "mirada": "No sé si con el paso del tiempo el nombre de Sebald [...] acabará originando un adjetivo, como los que acabo de mencionar. No sería extraño. Pero, entonces, si "sebaldiano" (¿sería así?) se convirtiera en un adjetivo, ¿a qué sustantivo debería acompañar? [...] [C] reo que si el adjetivo se acabara consolidando, el sustantivo al que terminaría asociado sería fundamentalmente "mirada". Hay una mirada sebaldiana sobre el mundo. Hay una manera de mirar específica de Sebald. Según cómo, en el caso de Sebald, es más relevante, específica, nueva, la forma de mirar que la cosa mirada. Más que un mundo de Sebald hay unos ojos de Sebald. [...] [N]acida fundamentalmente de la literatura, [su mirada] tiene influencia y sentido más allá de la literatura 
y ha teñido maneras de mirar de otras disciplinas artísticas o, acaso mejor, de otros formatos de la mirada humana, incluidas las artes visuales". VILLATORO, Vicenç, "La mirada de Sebald", en CARRIÓN, Jorge (dir.), Las variaciones Sebald / Sebald Variations, CCCB, Barcelona, 2015, p. 3.

6 WOOLF, "The New Biography"..., p. 154.

7 Cf. DEAN, Tacita, "W. G. Sebald", en October, n' 106 (2003), pp. 122-36; FOSTER, Hal, "An Archival Impulse", en October, no 110 (2004), pp. 3-22.

${ }^{8}$ Las variaciones Sebald..., p. 34.

${ }^{9}$ Se ha señalado con frecuencia el paralelismo entre Austerlitz y Nadja en el uso de las imágenes. Sobre la aprehensión sebaldiana del surrealismo, particularmente mediada por la lectura benjaminiana (no faltó, por cierto, quien viera en el personaje de Jacques
Austerlitz concomitancias con el propio Benjamin), cf. RYAN, Judith, "Fulgurations: Sebald and Surrealism", en The Germanic Review: Literature, Culture, Theory, vol. 82.3 (2007), pp. 227-49. Según la tesis que Ryan defiende, la esperanza de Benjamin en la posibilidad del desvelamiento, siquiera distante o incluso irónica, ha desaparecido en Sebald; la distancia, desde luego, la marcan los campos.

${ }^{10}$ Las variaciones Sebald..., p. 67.

11 "Sebald: doce variaciones y un epílogo", en Las variaciones Sebald..., p. 8.

${ }^{12}$ LONG, J. J., "W. G. Sebald: texto, imagen, artes", en Las variaciones Sebald..., pp. 17-23. Cf. su lectura foucaultiana de la obra de Sebald en $W$. G. Sebald: Image, Archive, Modernity, Edinburgh University Press, Edinburgh, 2007.
13 "El legado de Sebald: dos variaciones finales", en Las variaciones Sebald..., pp. 59-69, en la que a la conversación entre Elkins y Helguera se suma otra entre Jorge Carrión y Josep Maria Lluró. El catálogo incluye también un texto inteligente, como es lo usual en él, de Julià de Jòdar ("Proyecto para Sebald, con él y más allá de él", pp. 50-56), núcleo de su proyecto homónimo, y el registro de las instalaciones de los escritores Piedad Bonnett ( $L a$ luz en las cenizas. Relectura acotada de «Los anillos de Saturno»), Valeria Luiselli (Collected Poems) y Reinaldo Laddaga (La Baronesa Elsa von Freytag-Loringhoven, al regresar con Dane Rudhyar a su loft de una visita al Museo Metropolitano, le muestra su "Retrato de Marcel Duchamp" y luego lo acompaña en la ejecución de su "Sintonía"). 